\title{
A Study on the Effect of Pre-Pregnancy Body Mass Index and Gestational Weight Gain on Pregnancy and Neonatal Outcome
}

\author{
Prema Priya G. ${ }^{1}$, Suganya T. ${ }^{2}$, Karthik Sadasivam ${ }^{3}$, Senthilpriya S. ${ }^{4}$, Jeyamani B. ${ }^{5}$ \\ 1,2,3,4,5 Department of Obstetrics and Gynaecology, Vinayaka Missions Kirupanandavariyar \\ Medical College and Hospital, VMRF (DU), Salem, Tamilnadu, India.
}

\section{ABSTRACT}

\section{BACKGROUND}

Obesity has become a global epidemic. Maternal overweight and obesity is now a major challenge to the treating obstetricians. We intended to find the effect of pre pregnancy body mass index (BMI) and gestational weight gain during pregnancy on maternal and neonatal outcome.

\section{METHODS}

300 women with singleton pregnancy and spontaneous conception, who attended antenatal outpatient department (OPD) in our tertiary hospital, were included in this study after informed consent. The rate of gestational weight gain was calculated by subtracting the pre pregnancy weight from the final weight of the mother during last antenatal visit or during delivery. They were followed up and their maternal and perinatal outcomes such as anaemia, gestational hypertension, gestational diabetes, preterm labour, past dates, and intrauterine growth restriction, low birth weight, large for gestation, caesarean delivery and neonatal intensive care admission were studied.

\section{RESULTS}

The mean age of the woman in this study was $24 \pm 2$ years. Of them, $13 \%$ (n=39) of women were underweight. $40 \%(n=120)$ of women were of normal BMI. $33 \%(n=$ 99) of women were overweight. $14 \%(n=52)$ of women were obese. Maternal complications such as anaemia, preterm labour and intrauterine growth restriction were significantly common in underweight woman and inadequate gestational weight gain woman. Gestational diabetes, gestational hypertension, large for gestation baby and Caesarean deliveries were more in pre pregnancy obese woman and excess gestational weight gain woman.

\section{CONCLUSIONS}

An appropriate maternal pre pregnancy body mass index of 18.5 to $22.9 \mathrm{Kg} / \mathrm{m}^{2}$ at conception followed by an appropriate gestational weight gain (10 to $14 \mathrm{Kg}$ ) during pregnancy has a better maternal and neonatal outcome.

\section{KEY WORDS}

Body Mass Index, Gestational Weight Gain, Maternal Outcome, and Neonatal Outcome, Obese
Corresponding Author:

Dr. Prema Priya. G.,

Associate Professor,

Vinayaka Missions Kirupanadavariyar

Medical College and Hospital,

Salem, Tamilnadu, India.

E-mail:dr.premapriya.r@gmail.com

DOI: $10.14260 / \mathrm{jemds} / 2021 / 153$

How to Cite This Article:

Priya GP, Suganya T, Sadasivam K, et al. A study on the effect of pre-pregnancy body mass index and gestational weight gain on pregnancy and neonatal outcome. J Evolution Med Dent Sci 2021;10(10):715718, DOI: $10.14260 /$ jemds/2021/153

Submission 08-10-2020,

Peer Review 16-01-2021,

Acceptance 23-01-2021,

Published 08-03-2021.

Copyright () 2021 Prema Priya G. et al. This is an open access article distributed under Creative Commons Attribution License [Attribution 4.0 International (CC BY 4.0)] 


\section{BACKGROUND}

Despite the advancement in medical field, the rate of pregnancy complications and maternal mortality is still on the rise. There has been a dramatic increase in the prevalence of overweight and obesity worldwide. Obesity has become a global epidemic. Maternal overweight and obesity is now a major challenge to the treating obstetricians. Accumulation of excess body fat is obesity. Obesity can be diagnosed by various markers such as body mass index, waist to hip circumference, skin fold thickness, etc. ${ }^{1}$

Maternal overweight and obesity has a negative impact for both mother and the fetus. The overweight and obese mother is at the risk of abortion, preeclampsia, gestational diabetes, past dates, increased caesarean delivery, postpartum haemorrhage, puerperal infection and thromboembolism. ${ }^{2-5}$ The fetus is at the risk of increased congenital anomaly, macrosomia, stillbirth, perinatal morbidity and mortality. Obesity is also the risk factor for many familial health problems such as diabetes, hypertension, coronary artery disease, etc.

Malnourished mother has adverse effect on the mother and the fetus. Underweight BMI women are at the risk of anaemia, intrauterine growth retardation, and small for gestation age babies. Hence the nutritional status of the woman in reproductive age and gestational weight gain during pregnancy plays a major role in the maternal and neonatal outcome. The rate of gestational weight gain was calculated by subtracting the pre pregnancy weight from the final weight of the mother during last antenatal visit or during delivery.

According to Institute of Medicine (IOM) weight gain recommendations for pregnancy, gestational weight gain was classified into Inadequate weight gain: less than $11.5 \mathrm{Kg}$, Normal weight gain: 11.5 to $16 \mathrm{Kg}$ and Excessive weight gain: more than $16 \mathrm{Kg}$.

Body mass index is defined as the body mass in kilograms divided by the square of body height in metres. It is expressed as $\mathrm{Kg} / \mathrm{m}^{2}$. According to the Asian Pacific classification of BMI, people are classified as underweight $<18.5 \mathrm{Kg} / \mathrm{m}^{2}$, normal weight 18 . 5to $22.9 \mathrm{Kg} / \mathrm{m}^{2}$, overweight 23.0 to $24.9 \mathrm{Kg} / \mathrm{m}^{2}$ and obese $\geq 25 \mathrm{Kg} / \mathrm{m}^{2}$.

We intend to find the effect of pre pregnancy BMI and gestational weight gain on maternal and neonatal outcome.

\section{METHODS}

This was a prospective observational study done over one year from January 2019 to February 2020 in a tertiary hospital in Salem district of Tamilnadu. 300 women with singleton pregnancy with spontaneous conception who attended antenatal OPD in first trimester were included in the study. Multiple pregnancy, assisted reproductive technique conception, past or present medical disorders and those not willing for follow up were excluded. After informed consent, the women were included in the study. Those with known prepregnancy weight, pre pregnancy BMI was calculated using the formula $\mathrm{BMI}=$ weight in kilograms / height in metre square. The rate of gestational weight gain was calculated by subtracting the pre pregnancy weight from the final weight of the mother during last antenatal visit or during delivery.
They were followed up until delivery and their maternal and perinatal outcomes such as anaemia, gestational hypertension, gestational diabetes, preterm labour, past dates, intrauterine growth restriction, low birth weight, neonatal intensive care admission, respiratory distress syndrome, meconium stained liquor and large for gestational age were studied.

\section{Statistical Analysis}

The statistical analysis was done using SPSS 23. The data analysed were expressed in number, frequency and percentage. The chi square test of significance was applied. The P-value less than 0.005 considered as statistically significant. The sample size was calculated using Open Epi software version 3 . The sample size was calculated at $95 \%$ confidence interval and $5 \%$ error and it came out 300 .

\section{RESULTS}

300 women were included in this study. The mean age of the participants in this study was $24 \pm 2$ years. Table 1 describes the distribution of age in study participants. $41 \%(\mathrm{n}=123)$ of women were in the age group of 21 to 25 years. $30 \%(n=90)$ of women were in the age group of 26 to 30 years. $22 \%$ ( $n=$ 66) of women were in the age group of less than 20 years. $7 \%$ $(n=21)$ of women were in the age group of more than 30 years.

\begin{tabular}{|cc|}
\hline Age Group (Years) & $\mathbf{N}=\mathbf{3 0 0 ,} \mathbf{n}(\mathbf{\%})$ \\
$<20$ & $66(22)$ \\
$21-25$ & $123(41)$ \\
$26-30$ & $90(30)$ \\
$>30$ & $21(7)$ \\
\hline Table 1. Age Distribution & \\
\hline
\end{tabular}

Table 2 describes the distribution of gravida in the study participants. $48 \%(n=144)$ of women were primigravida. 25 $\%(n=75)$ of women were second gravida and $24 \%(n=72)$ of women were third gravida.

\begin{tabular}{|cc|}
\hline Gravida & $\mathbf{N}=\mathbf{3 0 0}, \mathbf{n}(\%)$ \\
1 & $144(48)$ \\
2 & $75(25)$ \\
3 & $72(24)$ \\
$>3$ & $9(3)$ \\
\hline Table 2. Distribution of Gravida \\
\hline \multicolumn{2}{|c}{} \\
\hline
\end{tabular}

Table 3 describes the distribution of maternal BMI in the study participants. $13 \%(n=39)$ of women were underweight. $40 \%(n=120)$ of women were of normal BMI. $33 \%(n=99)$ of women were overweight. $14 \%(n=52)$ of women were obese.

\begin{tabular}{|cc|}
\hline BMI $\left(\mathrm{Kg} / \mathbf{~ m}^{\mathbf{2}}\right)$ & $\mathbf{N}=\mathbf{3 0 0}, \mathbf{n}(\mathbf{\%})$ \\
\hline Underweight $<18.5$ & $39(13)$ \\
Normal 18.5 T0 22.9 & $120(40)$ \\
Overweight 23.0 T0 24.9 & $99(33)$ \\
Obese $\geq 25$ & $52(14)$ \\
\hline \multicolumn{2}{|c|}{ Table 3. BMI Distribution } \\
\hline \multicolumn{2}{|c}{}
\end{tabular}

\begin{tabular}{|cc|}
\hline Gestational Weight Gain (GWG) & N = 300, n (\%) \\
Inadequate weight gain $<11.5 \mathrm{Kg}$ & $102(34)$ \\
Normal weight gain $11.5-16 \mathrm{Kg}$ & $87(29)$ \\
Excess weight gain $>16 \mathrm{Kg}$ & $111(37)$ \\
\hline Table 4. Gestational Weight Gain (GWG) during Pregnancy \\
\hline
\end{tabular}


Table 5 describes the maternal complications. Anaemia was more common $50.9 \%$ with inadequate GWG women followed by $27.6 \%$ in normal GWG women and $13.5 \%$ in excess weight gain women. $(\mathrm{P}=0.07)$ statistically significant. Gestational hypertension was found in $30.6 \%$ with excess weight gain women followed by $24.1 \%$ with normal GWG and $6.8 \%$ with inadequate GWG women. Gestational diabetes was found in $19 \%$ of excess weight gain women. Preterm birth was more common in inadequate GWG women $29.4 \%(\mathrm{P}=0.04)$ statistically significant. Past dates were more in excess GWG women $22.5 \%$ followed by normal GWG women $10.3 \%$. Intrauterine growth restriction was found in $13.72 \%$ of inadequate GWG women.

\begin{tabular}{|c|c|c|c|c|}
\hline Complications & $\begin{array}{c}\text { GWG } \\
\text { Less Than } 11.5 \\
\text { Kg } \\
\mathbf{N}=102 \\
\text { n (\%) }\end{array}$ & $\begin{array}{c}\text { GWG } \\
\begin{array}{c}11.5 \text { to } 16 \mathrm{Kg} \\
\mathrm{N}=87 \\
\mathbf{n}(\%)\end{array}\end{array}$ & $\begin{array}{c}\text { GWG } \\
\text { More Than } \\
16 \mathrm{Kg} \\
\mathrm{N}=111 \\
\mathrm{n}(\%)\end{array}$ & P-Value \\
\hline Anaemia & $52(50.9 \%)$ & $24(27.6)$ & $15(13.5 \%)$ & 0.07 \\
\hline $\begin{array}{c}\text { Gestational } \\
\text { hypertension }\end{array}$ & $7(6.86 \%)$ & 21 (24.1 \%) & $34(30.6 \%)$ & 0.7 \\
\hline $\begin{array}{l}\text { Gestational } \\
\text { diabetes }\end{array}$ & nil & 9 (10.3 \%) & $21(19 \%)$ & 0.6 \\
\hline Preterm & $30(29.4 \%)$ & nil & $10(9 \%)$ & 0.04 \\
\hline Past dates & nil & $9(10.3 \%)$ & $25(22.5 \%)$ & 0.5 \\
\hline IUGR & $14(13.72 \%)$ & nil & nil & 0.88 \\
\hline
\end{tabular}

The rate of Caesarean delivery was more in excess gestational weight gain woman followed by normal and inadequate gestational weight gain women contributing $35 \%$, $23.2 \%$ and $20 \%$ respectively. There was no postpartum haemorrhage or wound infection.

Preterm and low birth weight neonates were common in inadequate GWG women. Large for gestation age babies was seen in excess GWG women $22 \%$. Neonatal intensive care admission was required in $18 \%$ of excess GWG women followed by $8 \%$ in inadequate GWG women. The P value was not statistically significant. Meconium stained liquor was found in $13.2 \%$ in excess GWG women.

\section{DISCUSSION}

Maternal nutrition plays a major role in nutrition for the baby. Both malnutrition and obesity have detrimental effect both to the mother and fetus. In the present study, mean age of the study population was $24 \pm 2$ years. Anaemia was significantly common in inadequate GWG women (P = 0.07). Gestational hypertension and gestational diabetes were more common in excess gestational weight gain woman. However, it was not statistically significant. In studies done by Uebe $\mathrm{K}$ et al. Abenhaim HA, John J, Athukorala C, Murakmi M et al. there was significant association of gestational diabetes and gestational hypertension in obese and excess GWG woman. ${ }^{6-9}$

In studies done by Park JH, Tsai LH, Bhattacharya S et al. obese and excess gestational weight gain woman were at increased risk of gestational hypertension, preeclampsia, gestational diabetes, preterm labour, macrosomia, induction of labour and Caesarean delivery. ${ }^{10-13}$ Tharihalli and
Thathagari found significant increase in pregnancy-induced hypertension (PIH) with increase in maternal obesity. ${ }^{14}$ Frederick et al. reported that for every $1 \mathrm{Kg} / \mathrm{m} 2$ rise in prepregnancy BMI there is $8 \%$ increase in preeclampsia. 15

Caesarean delivery was more, $35 \%$ in obese and excess GWG woman in this study. Cedergren, Denison, Doherty and Callaway et al. also reported increased Caesarean delivery with overweight and obese woman.16-19 In Denison et al. study, the high maternal BMI was associated increased likelihood of postdates and its complications. ${ }^{17}$

In the present study intrauterine growth restriction, preterm deliveries, neonatal intensive care admission were significantly higher in underweight woman. The P-values was statistically significant. In studies done by Murakmi M, Abenhaim HA and Sahu MT et al. there was significant association of underweight women with low birthweight, small for gestation age and intrauterine growth restriction infants. ${ }^{9,10,20}$ In studies done by Abenhaim HA, Athukorala C et al. concluded that increased pre pregnancy BMI was associated with increased adverse pregnancy outcomes. 7,9 Tsai IH et al. concluded that an appropriate maternal BMI (18.5 - $24 \mathrm{Kg} / \mathrm{m} 2)$ at conception with appropriate weight gain (10 - $14 \mathrm{Kg}$ ) during pregnancy has good maternal and fetal outcome.

The present study shows that both under nutrition and obese maternal BMI and excess GWG during pregnancy had adverse maternal and fetal outcomes. The results of this study emphasize the importance of good nutritional status of the woman before and during pregnancy for achieving the healthy pregnancy outcome. Maintaining normal BMI before pregnancy has good maternal and neonatal outcome in future.

\section{CONCLUSIONS}

Body mass index plays a major role in fertility, pregnancy and delivery. Underweight and obese women are at risk of maternal and fetal complications. Hence, pre pregnancy counselling should be given to women to maintain normal BMI. Lifestyle modification and weight reduction is advised in obese and overweight women. Thus, appropriate prepregnancy BMI and appropriate gestational weight gain during pregnancy has good impact on maternal and neonatal outcome.

\section{Limitations}

Small sample size. This study adds to the existing knowledge that inadequate and excess gestational weight gain during pregnancy has negative impact on the mother and fetus. Hence, pre pregnancy counselling should be given to woman of reproductive age to maintain normal BMI to achieve healthy pregnancy and childbirth.

Data sharing statement provided by the authors is available with the full text of this article at jemds.com.

Financial or other competing interests: None.

Disclosure forms provided by the authors are available with the full text of this article at jemds.com. 


\section{REFERENCES}

[1] Choudhary J, Singh S, Tiwari K. Study of BMI in pregnancy and its correlation with maternal and perinatal outcome. Int J Reprod Contracept Obstet Gynecol 2018;7(6):24729.

[2] Siega-Riz AM, Laraia B. The implications of maternal overweight and obesity on the course of pregnancy and birth outcomes. Matern Child Health J 2006;10(5 Suppl):S153-6.

[3] Andreasen KR, Andersen ML, Schantz AL. Obesity and pregnancy. Acta Obstet Gynecol Scand 2004;83(11):1022-9.

[4] Guelinckx I, Devlieger R, Beckers K, et al. Maternal obesity: pregnancy complications, gestational weight gain and nutrition. Obes Rev 2008;9(2):140-50.

[5] Heslehurst N, Simpson H, Ells LJ, et al. The impact of maternal BMI status on pregnancy outcomes with immediate short-term obstetric resource implications: a meta-analysis. Obes Rev 2008;9(6):635-83.

[6] Uebel K, Pusch K, Gedrich K, . Effect of maternal obesity with and without gestational diabetes on offspring subcutaneous and preperitoneal adipose tissue development from birth up to year-1. BMC Pregnancy Childbirth 2014;14:138.

[7] Abenhaim HA, Kinch RA, Morin L, et al. Effect of prepregnancy body mass index categories on obstetrical and neonatal outcomes. Arch Gynecol Obstet 2007;275(1):39-43.

[8] John J, Mahendran M. Maternal and fetal outcomes of obese pregnant women: a prospective cohort study. Int J Reprod Contracept Obstet Gynecol 2017;6(2):725-9.

[9] Athukorala C, Rumbold AR, Willson KJ, et al. The risk of adverse pregnancy outcomes in women who are overweight or obese. BMC Pregnancy Childbirth 2010;10:56.

[10] Murakami M, Ohmichi M, Takahashi T, et al. Prepregnancy body mass index as an important predictor of perinatal outcomes in Japanese. Arch Gynecol Obstet 2005;271(4):311-15.

[11] Park JH, Lee BE, Park HS, et al. Association between prepregnancy body mass index and socioeconomic status and impact on pregnancy outcomes in Korea. J Obstet Gynaecol Res 2011;37(2):138-45.

[12] Tsai IH, Chen CP, Sun FJ, et al. Associations of the prepregnancy body mass index and gestational weight gain with pregnancy outcomes in Taiwanese women. Asia Pac J Clin Nutr 2012;21(1):82-7.

[13] Bhattacharya S, Campbell DM, Liston WA, et al. Effect of body mass index on pregnancy outcomes in nulliparous women delivering singleton babies. BMC Public Health 2007;7:168.

[14] Tharihalli C, Thathagari V. Study of correlation between maternal body mass index with maternal and perinatal outcome. Int J Reprod Contracept Obstet Gynecol 2017;6(1):164-7.

[15] Frederick IO, Rudra CB, Miller RS, et al. Adult weight change, weight cycling and pre-pregnancy obesity in relation to risk of preeclampsia. Epidemiology 2006;17(4):428-34.

[16] Cedergren M. Effects of gestational weight gain and body mass index on obstetric outcome in Sweden. Int J Gynaecol Obstet 2006;93(3):269-74.

[17] Denison F, Price J, Graham C, et al. Maternal obesity, length of gestation, risk of postdates pregnancy and spontaneous onset of labour at term. BJOG 2008;115(6):720-5.

[18] Doherty DA, Magann EF, Francis J, et al. Pre-pregnancy body mass index and pregnancy outcomes. Int J Gynaecol Obstet 2006;95(3):242-7.

[19] Callaway LK, Prins JB, Chang AM, et al. The prevalence and impact of overweight and obesity in an Australian obstetric population. Med J Aust 2006;184(2):56-9.

[20] Sahu MT, Agarwal A, Das V, et al. Impact of maternal body mass index on obstetric outcome. J Obstet Gynaecol Res 2007;33(5):655-9. 